\title{
Pesquisas variacionistas nas regiões sul e sudeste do Pará: uma reflexão sobre a trajetória do Observatório de Linguagem do Sul e Sudeste do Pará (Olisspa)
}

\author{
Variationing research in South and Southeast regions of Pará: a reflection on \\ the path of the South and Southeast of Pará Language Observatory (Olisspa) \\ Eliane Pereira Machado SOARES* \\ Universidade Federal do Sul e Sudeste do Pará (UNIFESSPA)
}

\begin{abstract}
RESUMO: O grupo de pesquisa Observatório de Linguagem do Sul e Sudeste do Pará (Olisspa) foi criado em 2003, no âmbito da Faculdade de Estudos da Linguagem (FAEL) Campus de Marabá - ainda como parte da Universidade Federal do Pará - UFPA. Objetivo principal do grupo é o de investigar fenômenos variacionistas da realidade linguística das regiões sul e sudeste do Pará, como se pode ser comprovado nos diversos trabalhos já desenvolvidos e em andamento. Neste artigo, refletimos sobre a trajetória do Olisspa, os desafios passados e presentes, dentre os quais a limitação de infraestrutura e de recursos materiais, e, a despeito disso, as contribuições que o grupo tem dado à pesquisa da língua portuguesa nessas regiões, em especial da língua falada na cidade Marabá.
\end{abstract}

PALAVRAS-CHAVE: Variação Linguística. Falares. Pesquisa Linguística.

ABSTRACT: The South and Southeast of Pará Language Observatory (Olisspa) research group was created in 2003, within the scope of the Language Studies Faculty (FAEL) - Marabá Campus - still as a part of the Federal University of Pará - UFPA. The group main objective is to investigate variationing phenomenon of the linguistic reality of the south and southeast regions of Pará, as can be verified in several works already developed and in progress. In this article, we reflect on the Olisspa path, past and present challenges, among them the infrastructure and resources material limitation and, in spite of that, the group contributions has given to the Portuguese language research in these regions, specially of the language spoken in Marabá city.

KEYWORDS: Linguistic Variation. Spoken Language. Linguistic Research.

\section{Introdução}

A Universidade Federal do Pará instalou-se na região Sudeste do Pará em 1987, por meio do Campus Universitário de Marabá, a partir do projeto de interiorização da UFPA. Em 06 de junho de 2013 houve desmembramento do Campus que se tornou a Universidade Federal do Sul e Sudeste do Pará (Unifesspa), em conformidade com a Lei Federal n. ${ }^{\circ}$ 12.824, com sede e foro no Município de Marabá, região sudeste do Pará, sendo seguida pela criação de 4 campi, a saber, o de Rondon do Pará, Santana do

\footnotetext{
* Doutora. Professora de Linguística da Faculdade de Estudos da Linguagem (FAEL)-Instituto de Letras, Linguística e Artes (ILLA) - Universidade federal do Sul e Sudeste do Pará - Campus de Marabá-MarabáPará. E-mail: eliane@unifesspa.edu.br
}

Revista Moara, n. 54, ago-dez 2019 ISSN: 0104-0944

Recebido em 02/08/2019

Avaliado em 19/08/2019 
Araguaia, São Félix do Xingu e Xinguara. Dentre os diversos cursos já existentes, o curso de Letras encontra-se dentre os mais antigos e desde então vem arduamente buscando se estruturar para atender as demandas de ensino, pesquisa e extensão próprias do fazer acadêmico, em específico, aquelas de interesse do curso.

A elaboração de um Projeto Político pedagógico, em 2000, veio em grande parte atender às necessidades impostas e a uma proposta de autonomia do curso cujas concepções e princípios desde então norteiam a Faculdade de Estudos da Linguagem (FAEL), do Campus Universitário de Marabá. Em função disso, o Projeto Político Pedagógico (PPCL) em vigor desde 2004, se organiza em torno de duas grandes áreas do conhecimento: Estudos Linguísticos e Estudos Literários. As atividades curriculares se distribuem nessas duas áreas do conhecimento organizadas por quatro núcleos de interesse: Núcleo de Formação Básica; Núcleo de Formação Especifica; Núcleo de Educação e Diversidade Linguística e Cultural e Núcleo Leitura, Escrita e Produção de Sentidos. Tais temáticas refletem uma preocupação com uma dimensão formativa que contempla tanto a formação do docente quanto do pesquisador, de modo que possa dar conta tanto de aspectos relacionados às condições de ensino-aprendizagem no trabalho com a língua materna quanto ao trabalho com fenômenos linguísticos.

Pretende-se, pois, com tal formação, dar ao aluno condições de desenvolver hábitos de pesquisa, relacionados à linguagem, quando se reconhece o acolhimento e o trato da diversidade como um princípio formativo, de forma que é de bastante interesse a viabilização de projetos que venham a discutir fatos e situações diversas que cercam as questões de linguagem, tanto no que diz respeito à Língua Portuguesa quanto a outras línguas faladas em nossa região.

É nesta perspectiva que o Observatório de Linguagem do Sul e Sudeste do Pará (Olisspa) se insere. Seu principal interesse é o de fomentar e implementar, sobretudo, pesquisas variacionistas sobre o português falado e escrito, bem como sobre línguas indígenas faladas nessas regiões. Desde sua criação, muitos trabalhos foram realizados e há tantos outros em andamento, no nível de graduação e pós-graduação, que certamente contribuem para a compreensão da realidade linguística e sociolinguística nessas regiões.

Entretanto, um dos grandes entraves têm sido as limitações próprias de uma universidade pública do norte do país em expansão rumo ao interior: falta de recursos 
humanos e materiais. Os primeiros têm sido contemplados pela busca árdua de capacitação de seus docentes em níveis de pós-graduação e os segundos pela concorrência a editais que possibilitem o desenvolvimento da pesquisa em termos materiais, o que de fato tem sido um grande entrave, a despeito da imensa demanda de pesquisa que requer a realidade local.

\section{Diversidade e variação linguísticas no contexto das Regiões Sul e Sudeste do Pará}

As mesorregiões paraenses Sudeste e Sudoeste (ambas as regiões são mais conhecidas como Sul do Pará) têm sido pouco contempladas em termos de pesquisa, especialmente, do ponto de vista linguístico e mais ainda do sociolinguístico. Isso pode ser um grande prejuízo à compreensão da formação sócio histórica dessa parte do estado, sobretudo se levarmos em conta a complexidade da formação humana e sociocultural dessas regiões, que inclui o caboclo, o indígena, o afrodescendente e os provenientes de migrações de diferentes regiões do Brasil em consequência de interesses políticos diversos (como a ocupação da Amazônia no período da ditadura militar). Marabá, situada na região Sudeste, em particular tem sido palco de vários fatores históricos impactantes: os diversos ciclos econômicos como a extração do caucho; a coleta de castanha-do-pará; a abertura de estradas, como a Transamazônica, a partir dos anos 1970; a garimpagem (principalmente com a descoberta do garimpo de Serra Pelada nos anos 1980); a pecuária e a expansão do latifúndio; a extração de madeira; os grandes projetos como a construção de hidrelétrica de Tucuruí; a instalação da mineradora Vale do Rio Doce e mais recentemente a explosão do agronegócio. Esses fatos intensificaram as migrações de forma vertiginosa e tornaram a região uma das mais peculiares do estado, talvez do Brasil, tanto do ponto de vista ambiental quanto sociocultural. Consequentemente, para cá convergiram variedades linguísticas de todas as regiões do país, que coexistem com línguas de grupos indígenas de várias etnias ${ }^{1}$.

É essa complexidade que caracteriza o Sul e Sudeste do Pará como regiões de fronteira, e que as aproximam do ponto de vista de suas especificidades em vários

\footnotetext{
${ }^{1}$ Região sudeste: Assurini do Tocantins, Gavião, Parakanã, Suruí, Xicrin do Cateté, Anambé, Manayé, Tembé, Turiwara. Região sul (Parque indígena do Xingu): Aweti,Ikpeng, Kalapalo, k amaiurá, Kuikuro, Matipu, Mehinako, Nahukua, Naruvotu, Wauja, Tapayuna, Trumai. Yudja, Yawalapiti. Fonte: http://www.funai.gov.br/index.php/indios-no-brasil/o-brasil-indigena-ibge. Acesso em 24/05/2019.
} 
aspectos e as diferenciam em relação às demais regiões do estado do Pará ${ }^{2}$, cuja imensidão territorial, por si mesma, o torna uma fonte inesgotável de observação científica sob diversos prismas teóricos. Sem dúvida, os aspectos linguísticos e culturais que nelas se somam e se interpenetram fazem com que a configuração e os conflitos resultantes dificilmente são percebidos em sua totalidade.

De fato, as diferenças entre essas regiões face às demais são bastante perceptíveis em diversos aspectos: socioeconômicos, culturais e linguísticos. É na perspectiva da pesquisa linguística associada aos aspectos socioeconômicos e culturais que propusemos o grupo de pesquisa Olisspa, considerando seu potencial para melhor se entender essas regiões.

\section{Dos objetivos e das metas do Olisspa}

Apesar de seu registro no CNPQ só ter se efetivado em 2010, a criação do Olisspa de fato se dá em 2003, como programa de pesquisa, aprovado no âmbito da faculdade a que nos integramos - FAEL, a partir da defesa da dissertação de mestrado Realizações da nasal e lateral palatais no falar de Marabá (Soares, 2002) e firmado em tese de doutorado As palatais lateral e nasal no falar paraense: uma análise variacionista e fonológica (Soares, 2008). Desde então, trabalhos de pesquisa e extensão têm sido realizados no sentido de implementar os objetivos que fundamentam sua existência.

Os objetivos para o Olisspa foram traçados em consonância com a realidade e as necessidades da pesquisa voltadas para a diversidade e variação linguísticas. Assim definimos como objetivo central e geral a constituição, documentação e análise de corpora orais e escritos das regiões Sul e Sudeste do Pará, tendo em vista outros objetivos mais particulares tais como: contribuir para a consolidação de ações previstas no Projeto Político Pedagógico do Curso de Letras; promover atividades de pesquisa e extensão como fortes elementos constitutivos do processo formativo do aluno e futuro profissional de Letras; promover atividades de formação no campo da descrição e análise linguísticas; fomentar a pesquisa linguística nas regiões Sul e Sudeste do Pará na

\footnotetext{
${ }^{2}$ Foi o que pudemos constatar em nossa tese de doutorado, na qual tratamos dados linguísticos, especificamente, a lateral e a nasal palatais, das principais cidades de todas as mesorregiões do estado do Pará.

Revista Moara, n. 54, ago-dez 2019 ISSN: 0104-0944

Recebido em 02/08/2019

Avaliado em 19/08/2019
} 
correlação da diversidade e variação linguísticas e ensino-aprendizagem de língua, com o propósito de construir alternativas para a superação de problemas relacionados (por exemplo, variantes escritas em decorrência das interferências da fala); contribuir para consolidação de um Programa de Ensino, Pesquisa, Extensão; inserir alunos de Iniciação científica na prática de construção do conhecimento; fomentar estudos de descrição e análise de aspectos linguísticos do português nos níveis fonético-fonológico, morfossintático e semântico-lexical dos falares urbanos e rurais e de línguas indígenas; contribuir para o fortalecimento da pesquisa no curso de Letras em Marabá voltada para a investigação de línguas indígenas faladas nas regiões Sul e Sudeste do Pará e aspetos relacionados à educação escolar indígena; contribuir para consolidação de um Programa de Ensino, Pesquisa, Extensão preocupado com o ensino de língua portuguesa na região, quer seja $\mathrm{L}_{1}$ quer seja como $\mathrm{L}_{2}$ em comunidades bilíngues em comunidades indígenas.

Percebe-se que, pelos objetivos, as metas a serem alcançadas devem ampliar as condições de produção científica, do ponto de vista humano e material, bem como a própria produção científica. Dessa forma, para a consolidação do Olisspa vislumbramos as seguintes metas: fornecer formação específica a alunos de graduação em Letras no campo de pesquisa de usos da língua falada; adquirir sala própria, fomentos, equipamentos e materiais permanentes que viabilizem a pesquisa; formar um banco de dados de fala em diferentes contextos de produção oral; formar um banco de dados com textos escritos por autores considerados "regionais"; formar um banco de dados de textos escritos produzidos em ambiente escolares; promover eventos (cursos, encontros, simpósios, seminários) com estudiosos com o objetivo de fornecer formação específica teórica e metodológica; participar de eventos (cursos, encontros, simpósios, seminários) com estudiosos com o objetivo de fornecer formação específica teórica e metodológica adequada aos temas desenvolvidos; Orientar Trabalhos de Conclusão de Curso; selecionar bolsistas de bolsas de pesquisas (IC, BIA etc), conforme editais; desenvolver projetos de ensino e de extensão correlacionados à pesquisa; criar uma publicação (boletim científico) para divulgação de trabalhos de descrição e análise linguística de aspectos da língua falada e escrita no Sul e Sudeste do Pará e aspectos de ensinoaprendizagem correlacionados à essa temática; criar um grupo de estudos para discussões permanentes. 
Como discutiremos mais adiante, muitos desses objetivos e metas sofrem as duras restrições das condições materiais impostas pelas circunstâncias que envolvem a educação no Brasil.

\section{Suporte teórico e metodológico}

A constituição de um projeto de pesquisa com os objetivos do Olisspa implica necessariamente a adoção de procedimentos metodológicos em dois níveis: no nível da formação de recursos humanos e no nível do aporte teórico-metodológico.

No que tange à formação de recursos humanos, o Olisspa se apresenta como parte dos esforços do PPCL de fazer da pesquisa o princípio formativo do estudante de graduação. Por essa razão, a formação desse grupo de pesquisa exige procedimentos indispensáveis que incluem: seleção e aquisição de bibliografia pertinente; estudos bibliográficos; reuniões de estudos e debates de pesquisadores (professores e alunos); definição de projetos de pesquisas; seleção de monitores e bolsistas PIBIC, BIA etc. Todas essas condições necessárias à existência do OLISSPA.

Quanto à linha teórico-metodológica, é necessário dizer que o ponto de partida teórico que fundamenta esta proposta é o dos estudos variacionistas, segundo os quais o estudo de uma língua em uso é uma das formas de se conhecer a comunidade que a utiliza. Isso é possível por que as manifestações linguísticas de um grupo (marcadas por particularidades fonético-fonológicas, morfossintáticas, semântico-lexicais) são pistas importantes para o conhecimento tanto da história quanto do momento atual da vivência de uma comunidade, devido ao fato de as línguas serem fenômenos inerentes, indispensáveis à constituição das sociedades humana, sendo, pois, portadoras de cultura e veículo para sua transmissão, de forma que conferem tanto uma identidade individual quanto social, bem como contribuem para a construção da autoestima e da autoafirmação de pessoas e grupos. Por essa razão, uma língua representa um conjunto de saber acumulado, único, insubstituível; ela traz conhecimentos que dizem respeito à experiência e à sobrevivência humana. Ela nomeia seres, objetos, modos de fazer, modos de viver, de se relacionar com outros e com o meio ambiente essenciais à vida humana, que permitem a cada povo em particular e de modo particular se adaptar e sobreviver ao longo de sua trajetória no planeta e que tem muito a ensinar a outros 
povos. Uma língua, portanto, traz uma ciência que se perde para sempre com a sua extinção.

Deve-se ainda ressaltar que as línguas, todas elas, são sistemas altamente complexos que, ao serem estudados de forma particular, podem ajudar a compreender o funcionamento cognitivo humano em geral, pois demonstram como o ser humano codifica a compreensão do mundo nas estruturas linguísticas, bem como reflete nessa mesma estrutura as marcas trazidas das relações sociais, dos modos de organização e hierarquização social, de forma que a fala de um individuo demonstra sua origem social e geográfica, bem como seu papel social numa dada situação de interação verbal em diferentes contextos.

Assim, o estudo das línguas de um modo geral e, especialmente, das diferenciações linguísticas permite-nos conhecer não somente a língua em si mesma ou por si mesma, mas também permite compreender os modos de funcionamento de um grupo social. Como falantes de língua portuguesa, não é difícil constatarmos diferenças regionais e sociais, entretanto, o que pode parecer caótico e sem explicação, torna-se bastante justificado na perspectiva da compreensão das línguas como um conglomerado de variantes sistematizáveis, por meio de ferramentas computacionais, sendo elas perfeitamente ajustadas às necessidades dos grupos que as utilizam e ao sistema linguístico, formando, elas mesmas, subsistemas. Tais reflexões encontram embasamento em diversos autores, dentre os quais destacamos: Labov (1972, 1994, 2001), Milroy (1987); Mollica e Braga (2004); Naro (2004), Pintzuk (1988), Tarallo (1990), Bagno (2003), Cardoso e Ferreira (1994), Elia (1987), Guy e Zilles (2007), Milroy (1987), Bortoni-Ricardo (1985; 2011).

A coleta de dados linguísticos se dá conforme os aportes oferecidos pela Sociolinguística Quantitativa, pela Geosociolinguística e pela Etnografia da Comunicação, conforme objetivos e etapas próprias de cada coleta/pesquisa. Para tanto, são imprescindíveis: a seleção de falantes/informantes adequados a esses objetivos; o registro da fala em situações diversas em diferentes normas, gêneros de interações verbais e modalidades da língua, de acordo com uma metodologia adequada para cada fim.

Assim, a seleção de falantes se faz de acordo com os objetivos imediatos de cada pesquisa, mas a composição da amostra em área urbana com finalidades 
sociolinguísticas segue a proposta do Atlas Linguístico do Pará (RAZKY, 1998), com adequações. Assim, a seleção se faz sobre falantes nascidos na área urbana da cidade cuja estratificação social levará em conta os seguintes critérios: a) ser nascido ou ter vindo para essa cidade com até cinco anos de idade; b) deve ter pais nascidos na cidade ou nela residentes desde a infância; c) não ter se ausentado da cidade por um período superior a 02 anos; d) residir na cidade e) enquadrar-se em uma das células quanto ao sexo, faixa etária $(A=15-25 \operatorname{anos} ; B=26-46$ anos; $C=+46$ anos; $)$ e escolaridade $(1=$ até 4 anos; $2=$ até 9 anos; $3=$ acima de 9 anos).

O registro de dados orais deve ser feito por meio de gravação de áudio (e vídeo, conforme objetivos) em condições as mais naturais possíveis, por meio de instrumentos de coleta adequados aos objetivos estabelecidos. Cada registro em áudio por informante, no caso de narrativas, deve no mínimo conter 45 (quarenta e cinco) minutos e, no máximo, de 60 sessenta minutos, e nos demais casos deve adequar-se às necessidades e condições imediatas. O tratamento dos dados obtidos se faz primeiro pela digitalização, a fim de serem arquivados, para posterior transcrição - grafemática, conforme orientações da Análise da Conversação e do Projeto NURC; transcrição fonética, pelo uso do Alfabeto Fonético Internacional (IPA) ou ainda ortográfica conforme os objetivos estabelecidos para a descrição e análise. Em função disso, os dados podem ser submetidos, por exemplo, à utilização de programas computacionais para arquivamento e ou tratamento estatístico conforme a natureza e o objeto da pesquisa (programas como Goldvarb, dentre outros disponíveis). A coleta de dados da fala da zona rural se norteia pela proposta do ALiB (Atlas Linguístico do Brasil, 2001).

Os dados linguísticos orais abrangem textos de diferentes tipos: narrativas de experiência pessoal, recontada; de descrição de local; relato de procedimento, de opinião; textos conversacionais; em função disso, os instrumentos de pesquisa, para obtenção de dados abrangem questionários semântico-lexicais e entrevistas, dentre outros instrumentos de coleta de dados linguísticos necessários aos objetivos de pesquisa imediata.

A inserção dos pesquisadores no lócus de pesquisa é fundamental para coleta de dados de fala, para a observação e a coleta, com a gravação de áudio e imagem, se necessário, conforme as circunstâncias de pesquisa. De igual modo, a seleção de informantes se adéqua aos propósitos pretendidos e à orientação metodológica mais 
imediatamente relacionada ao objeto especifico de cada pesquisa (nível linguístico de descrição; falar urbano, rural; gênero de texto; fala espontânea, conversação; texto oral, escrito; texto escrito em ambiente escolar, de autores regionais; língua portuguesa, língua indígena; língua comum, de grupos profissionais, étnicos) e aos objetivos pretendidos.

Assim, no caso de nosso projeto, o rigor metodológico se atém aos aspectos teórico-metodológicos apropriados a cada pesquisa, e se circunscreve no âmbito de um dos campos anteriormente citados, de modo a dar conta das manifestações linguísticas das regiões Sul e Sudeste do Pará. Por questões de restrição de recursos materiais e humanos, nosso enfoque é sobre a região sudeste, com ênfase em Marabá e circunvizinhança, mas esperamos poder realizar trabalhos em cidades mais distantes (para isso depende-se dos fomentos), bem como colaborar com pesquisas em parceria com iniciativas de pesquisadores dos demais campi da Unifesspa.

\section{Dos trabalhos realizados}

Desde sua criação, vem-se implementando a formação de grupos de estudos com os alunos de graduação e a orientação de Trabalhos de Conclusão de Curso e dissertações em nível de especialização e mestrado voltados para os fenômenos de variação linguística da língua portuguesa falada e escrita. Para tanto, além de uma dissertação de mestrado e uma tese de doutorado de nossa autoria, já mencionadas, sob nossa orientação foram desenvolvidos mais de 30 de Trabalhos de Conclusão de Curso e 05 em andamento; 6 Projetos de Pesquisa, 02 Projetos de Extensão; 01 Bolsa de iniciação científica (CNPQ), 04 bolsas PROINT e 02 bolsas de extensão. A produção resultante tem sido divulgada por meio de artigos e em congressos nacionais e internacionais, realizados no Brasil e no exterior ${ }^{3}$. Em contribuição aos estudos sobre as línguas indígenas na região, desenvolvemos uma pesquisa sociolinguística associado a um projeto de extensão em uma aldeia indígena da região, com vistas a contribuir para a educação escolar indígena desenvolvida na comunidade: Projeto de pesquisa: Situação Sociolinguística da aldeia indígena Kyikatêjê Amtátí (2009-2011) e Projeto de Extensão: Assessoria Linguística à Educação escolar Indígena na aldeia indígena

\footnotetext{
${ }^{3}$ Informações detalhadas podem ser encontradas em meu currículo na Plataforma Lattes e no Diretório de grupos de pesquisas do CNPQ: http://lattes.cnpq.br/6059414959775854.
} 
Kyikatêjê Amtátí (2010-2013). Em nível de especialização, foi defendida uma monografia, em nível de Mestrado profissional há 4 dissertações em andamento, e 04 dissertações defendidas, sob nossa orientação; no mestrado acadêmico há $03 \mathrm{em}$ andamento. Vale lembrar que ambos os mestrados foram implementados a partir de 2016.

Nesse momento, desenvolvemos uma pesquisa financiada pelo CNPQ (20172020), sobre Vocabulário de João Brasil, autor memorialista de Marabá, com o objetivo de estabelecer relações entre língua e a memória cultural local. O referencial teórico e metodológico remete à análise léxico-semântica de lexias, organizadas em campos lexicais (Coseriu, 1979) e aos estudos da Lexicologia, Lexicografia e Terminologia. Para a manipulação dos dados lexicais é utilizado o programa computacional LexiquePro, que permite construir dicionários eletrônicos. O trabalho se encontra em andamento e a previsão de término é em agosto de 2020.

Em suma, considerando os trabalhos concluídos e em andamento, pode-se dizer que a questão da diversidade e da variação linguística é tratada sob diferentes abordagens e com diferentes objetivos: pesquisa socioterminológica; pesquisa variacionista do português paraense; pesquisa da sócio-história do português paraense falado no Sul e Sudeste do Pará; pesquisa de linguística indígena integrada à educação indígena no Sudeste do Pará.

Com isso, procura-se dar conta da complexidade dos usos linguísticos nessas regiões, marcadas pela grande extensão territorial e, sobretudo, pela diferenciação de origem geográfica, social e cultural de seus falantes.

\section{Tarefas e desafios ao Olisspa: das dificuldades encontradas}

A despeito dos trabalhos produzidos ao longo desses anos, muitas das propostas do OLISSPA não puderam ainda ser realizadas, pois esbarraram em sérias dificuldades humanas e materiais, podemos facilmente elencar alguma delas:

- Infraestrutura: o Olisspa não ocupa nenhum espaço físico no Campus Universitário de Marabá. Um espaço inicial foi solicitado a então coordenação do campus,em 2002; de fato, o espaço foi cedido ao Olisspa informalmente, entretanto, havia uma questão legal, pois espaço era ocupado na época por uma livraria particular que entrou em litígio com a universidade por questões outras e o espaço, quando 
finalmente liberado, atendeu a outro projeto. Em 2009, encaminhamos solicitação formal de espaço à coordenação de então, mas não obtivemos resposta. Essa falta de espaço tem comprometido largamente nosso projeto, devido o trabalho com dados linguísticos demandar equipamentos e audição e transcrição de dados. Assim, os trabalhos se desenvolvem na residência da coordenadora e dos bolsistas e colaboradores do projeto. Vale lembrar que o curso de Letras dispõe de uma única sala à pesquisa e extensão que agrega todos os grupos de pesquisa da faculdade, inclusive faz atendimento externo, portanto há sempre um certo número de pessoas no ambiente, o que não convém ao nosso tipo de trabalho, pois, embora exija espaço próprio, o que é demais requerer na conjuntura atual, requer minimamente um ambiente mais adequado.

- Material Bibliográfico: todo material bibliográfico que dá suporte ao Olisspa provém da biblioteca, que infelizmente tem poucas obras atualizadas no tema, e da biblioteca pessoal da coordenadora do grupo de pesquisa, bem como obras disponíveis para download na internet.

- Equipamentos: o Olisspa só recentemente conta com equipamento (gravador, câmera de vídeo) provindo de fomentos.

- Fomento: ao longo desses anos, a despeito da nossa candidatura e editais de fomento, somente em 2017 tivemos projeto aprovado (edital universal 001/2016) com recurso para bolas de iniciação à pesquisa científica e compra de equipamentos. Fora a questão do mérito, em parte atribuímos isso às especificidades dos editais e da imensa concorrência que se faz entre pesquisadores, como também à política de indigência implementada no país para certos setores da pesquisa, consideradas não produtivas.

A parte humana do projeto também tem sido um dos grandes entraves, pois, como única professora pesquisadora da área há uma imensa sobrecarga de trabalho, o que nos fez concentrar a pesquisa na região sudeste, onde o campus se situa e a maior parte dos alunos se concentra., o que nos faz pensar em breve em reformular o nome do grupo, delimitando nosso trabalho para essa área em definitivo.

A despeito das dificuldades e do muito ainda a conquistar, o Olisspa tem se feito presente no fazer acadêmico e na construção do conhecimento de nossa região, em particular do sudeste do Pará, como se pode constatar pelos muitos trabalhos realizados e os em andamento. 


\section{Considerações finais: ou ainda há muito a se dizer e a fazer}

Como buscamos demonstrar anteriormente, o Olisspa é fruto de um esforço constante de produzir pesquisa linguística na/da região onde se encontra a universidade pública na qual atuamos, com isso reforçamos a proposta de inserção do curso de Letras na realidade local, bem como fundamenta a existência da própria instituição de ensino na região, procurando fazer jus ao princípio da indissociabildade entre ensino, pesquisa e extensão, tão caro à universidade.

Assim, os esforços envidados pelo Olisspa se integram ao esforço da própria da universidade em se constituir não somente como um espaço de formação profissional, mas, principalmente, de formação de homens e mulheres em condições de contribuir para a reconfiguração das relações sociais e econômicas, a partir de um ponto de vista que leve em conta o ser humano em suas diversas necessidades e sentimentos. Isso quer dizer, formar seres humanos capazes de compreender o espaço em que vivem e contribuírem com sua atividade profissional e social para a melhoria desse espaço, levando em conta o humano, o social e o meio ambiente.

Nesse contexto, a universidade, desde sua implantação em Marabá, em 1987, tem atuado na formação e qualificação de docentes e pesquisadores em diferentes áreas, de forma que vem contribuindo significativamente para a universalização da educação em todos os níveis. Nesse contexto, o curso de Letras pode ser pode ser considerado um curso pioneiro em vários aspectos, pois é comprometido com a pluralidade étnica, cultural, linguística e biológica, aspectos pelos quais que é reconhecido pela sociedade local como um dos cursos mais engajados na produção de saberes científicos, na formação de sujeitos, e com a promoção de conhecimentos. Como se vê, o OLISSPA se insere numa pauta histórica e só tem se mantido por conta do trabalho desenvolvido em sala de aula que tem atraído os alunos para atuarem, em maioria, como colaboradores no projeto, daí as pesquisas resultantes.

Entretanto, isso ainda não é suficiente. Infelizmente e lamentavelmente, faltamnos condições novas, ampliadas para que os estudos possam a vir a se desenvolver de forma mais sistemática e com as condições materiais mais adequadas, diferentemente das que temos enfrentado durante todos esses anos. Parece-nos que isso é um importante passo para a consolidação da pesquisa linguística nessas regiões e 
certamente poderemos contribuir para que se conheça mais o português brasileiro em uso, bem como as línguas étnicas dessas regiões.

\section{REFERÊNCIAS}

COMITÊ NACIONAL DO PROJETO ALiB. Atlas linguístico do Brasil: questionário. Londrina: Ed. UEL, 2001

COSERIU, E. O homem e sua linguagem. Rio de Janeiro: Presença, 1982.

ELIA, Silvio. Sociolingüística: uma introdução. Rio de Janeiro: Padrão, 1987.

FERREIRA, C; CARDOSO, S. A. A dialetologia no Brasil. São Paulo: Contexto, 1994.

GUY, Gregory R. ZILLES, Ana. Sociolingüística Quantitativa. São Paulo, Parábola Editoria, 2007.

LABOV, W. Principles of linguistic change: social factors. Oxford: Blackwell, 2001.

LABOV, W. Sociolinguistes patterns. Philadelphia: University of Pensylvania Press, 1972a.

MILROY, L. Observing \& analysing natural language: A critical account of Sociolinguistic Method. Oxford: Blackwell, 1987.

MOLLICA, M. C.; BRAGA, M. L. Introdução à sociolingüística: o tratamento da variação. São Paulo: Contexto, 2004.

NARO, A. J. Modelos estatísticos e tratamento estatístico. In: MOLLICA, Maria Cecília. (org.). Introdução à sociolingüística variacionista. 3 ed. Cadernos Didáticos. Rio de Janeiro: UFRJ, 1996.

PINTZUK, S. Programas VARBRUL. Trad. Ivone Isodoro Pinto. Rio de Janeiro: UFRJ, 1988.

RAZKY, Abdelhak. O Atlas Geosociolingüístico do Pará: Abordagem Metodológica. In: A geolingüística no Brasil: caminhos e perspectivas. Londrina:UEL, 1998. p. 155164.

SOARES, E. P. M. Variações dos fonemas palatais lateral e nasal no falar de Marabá-PA. Dissertação de Mestrado/ Doutorado em Linguística. Programa de pós Graduação em Letras. Universidade Federal do Pará. Belém, 2002. 
SOARES, E.P. M. As palatais lateral e nasal no falar paraense: uma análise variacionista e fonológica. Doutorado em Linguística. Centro de Humanidades. Fortaleza, Universidade Federal do Ceará, 2008.

TARALlO, Fernando. A pesquisa sociolinguística. São Paulo: Ática, 1990. 